\title{
Breast softness in patients randomised to postmastectomy breast reconstruction with an expander prosthesis or DIEP flap
}

\author{
Linda Tallroth $^{1}{ }^{1} \cdot$ Håkan Brorson ${ }^{1} \cdot$ Nathalie Mobargha $^{1} \cdot$ Patrik Velander $^{1} \cdot$ Stina Klasson $^{1} \cdot$ Magnus Becker $^{1}$
}

Received: 24 February 2021 / Accepted: 10 May 2021 / Published online: 1 June 2021

(c) The Author(s) 2021

\begin{abstract}
Background Objectively measured breast softness in reconstructed breasts and its relation to patients' subjective satisfaction with breast softness has not yet been investigated. The aim of this study was to evaluate breast softness in patients 1 year following delayed breast reconstruction with an expander prosthesis (EP) or deep inferior epigastric perforator (DIEP) flap, using objective and subjective methods.

Methods Seventy-three patients were randomised to breast reconstruction with an EP or DIEP flap between 2012 and 2018. Of these, 69 completed objective evaluation at a mean of 25 (standard deviation, SD 9.4) months following breast reconstruction. Objective evaluation included measurements of breast volume, jugulum-nipple distance, clavicular-submammary fold distance, ptosis and Baker scale grading. Breast softness was assessed with applanation tonometry. Subjective evaluation was performed using the BREAST-Q questionnaire.

Results Objectively, DIEP flaps were significantly softer than EP breast reconstructions. Non-operated contralateral breasts were significantly softer compared with reconstructed breasts. In the subjective evaluation, the median score on the question (labelled 1.h) "How satisfied or dissatisfied have you been with the softness of your reconstructed breast (s)?" was higher in the DIEP flap group corresponding to greater satisfaction in this group. A fair correlation was found between the applanation tonometry and the patient-reported satisfaction with the reconstructed breast's softness $\left(r_{s}=0.37\right)$.

Conclusions In terms of breast softness, breast reconstructions with DIEP flaps result in more satisfied patients. Concerning applanation tonometry as an objective tool for softness assessment, future studies on interobserver agreement are warranted. Level of evidence: Level I, therapeutic study
\end{abstract}

Keywords Breast reconstruction · Expander prosthesis · Deep inferior epigastric perforator (DIEP) flap · Applanation tonometry $\cdot$ Softness $\cdot$ BREAST-Q

\section{Introduction}

Following modern breast cancer treatment, patients are offered breast reconstruction to mitigate the negative outcomes of a mastectomy. Breast reconstruction after mastectomy has demonstrated increased patient satisfaction and quality of life (QOL) [1]. The goal is to reconstruct a new breast with a natural appearance. The evaluation of

Stina Klasson and Magnus Becker are joint senior authors.

Linda Tallroth

linda.tallroth@med.lu.se

1 Plastic and Reconstructive Surgery, Skåne University Hospital, Department of Clinical Sciences in Malmö, Lund University, Malmö, Sweden outcomes following breast reconstruction guides future surgical development and provides valuable information to patients in their decision-making process. Consequently, the validated patient-reported outcome measurement BREASTQ emerged [2]. BREAST-Q was developed through qualitative research as well as a literature review, in order to capture the patient's perspective in relation to breast surgery [3, 4].

One question in the BREAST-Q Postoperative Reconstructive Module concerns the softness of the reconstructed breast. Hence, the degree of breast softness influences patient satisfaction. In previous reports, objective evaluation of softness has been addressed in the context of capsular contracture [5-13]. Capsular contracture is one of the major complications that may follow implant-based breast reconstruction, resulting in a harder breast. Applanation tonometry is a method used for assessment of breast softness and 
capsular contracture and was introduced by Moore [14]. It is performed by placing a tonometer with a certain weight on the breast, generating a force. The imprint area read from the tonometer is used to estimate the intramammary pressure through the formula Pressure $=$ Force/Area [14]. Apart from investigating capsular contracture, applanation tonometry has been used for symmetrical comparison of two autologous breast reconstruction methods [15]. A more popular method that includes a breast softness assessment is the Baker classification scale, developed for diagnosis of capsular contracture. It is a four-grade scale and grades III-IV correspond to a symptomatic hard breast defined as showing capsular contracture [16]. The Baker scale is based on a combination of clinical palpation and breast appearance and is thus dependent on the examiner's experience and subjective assessment [17].

There are various breast reconstruction methods available today, comprising implant and autologous alternatives. To our knowledge, no investigation comparing breast softness following autologous or implant-based reconstruction has yet been performed. In addition, the association between the reconstructed autologous breast and the contralateral healthy breast is unknown. Our hypothesis is that autologous breast reconstruction using the deep inferior epigastric perforator (DIEP) flap results in softer breasts compared to reconstruction using an expander prosthesis (EP), resulting in patients with the DIEP flap reconstruction being more satisfied in terms of breast softness.

The primary aim of this study was to compare breast softness measured with applanation tonometry in patients randomised to unilateral breast reconstruction with an EP or DIEP flap. Comparison of reconstructed breasts with contralateral breasts was a secondary aim. A third aim was to investigate the relationship between tonometry measurements and the BREAST-Q question "How satisfied or dissatisfied have you been with the softness of your reconstructed breast (s)?".

\section{Material and methods}

\section{Study design}

The patients included in this study are enrolled in a randomised study conducted at our clinic [18]. Briefly, between 2012 and 2018, 73 patients who had undergone modified radical mastectomy were randomised to delayed breast reconstruction with an EP or DIEP flap. Study participation gave non-irradiated breast cancer patients the possibility to be reconstructed with a DIEP flap. At that time, the national guidelines suggested DIEP flaps should be offered only to patients who had previously undergone radiation therapy (RT) to the breast. A description of the randomisation process, including inclusion and exclusion criteria and reasons for participant drop out, was presented in our previous report [18]. Implant breast reconstruction is low-invasive, and since the development of the EP with a detachable port, often only one operation is required. The EP used in this study was a Siltex Mentor ${ }^{\circledR}$ Contour Profile Becker-35, Cohesive I (Johnson \& Johnson Medical Ltd, New Brunswick, New Jersey 08,933, USA). In contrast, breast reconstruction with autologous abdomen-based tissue, as with the DIEP flap, is a more extensive and technical operation. The DIEP flap has gained increased popularity over recent decades and is currently the gold standard in autologous breast reconstruction internationally and at our clinic.

\section{Patients}

Patient characteristics and follow-up times are presented in Table 1. The mean age at follow-up was 54 (standard deviation, SD 9.4) years. Of the 73 patients included in the randomised study, 69 completed objective examination at a mean of 25 (SD 9.4) months following breast reconstruction. Four patients were not evaluated. Two patients were waiting for a nipple reconstruction, one for a second opinion and one cancelled several follow-up appointments. Patient data was collected from medical journals and subsequently transferred to a document and coded. Informed and written consent was collected before the initial breast reconstruction procedure.

\section{Contralateral surgery and prosthesis exchange}

Patients were offered contralateral breast surgery to achieve symmetrical results. Thirty-one patients had contralateral surgery at a mean of 18 (SD 8.0) months prior follow-up. In the EP group, comprising 28 patients, contralateral surgery was performed on 15 patients, whereof nine were reduction mammaplasties and six were mastopexies. Of the 41 patients in the DIEP group, 15 underwent reduction mammaplasties and one a mastopexy.

Six patients in the EP group had a prosthesis exchange before the objective evaluation. One patient received a Mentor® Siltex Round, Moderate Plus Profile, Cohesive I (Johnson \& Johnson Medical Ltd, New Brunswick, NJ, 08,933, USA), three changed to a Mentor® CPG 312, Moderate Plus Projection, Cohesive III (Johnson \& Johnson Medical Ltd, New Brunswick, NJ, 08,933, USA), and two to a Mentor® CPG 313, High Projection, Cohesive III (Johnson \& Johnson Medical Ltd, New Brunswick, NJ, 08,933, USA). Two exchanges were the result of capsular contracture (6 and 24 months following primary breast reconstruction), one of asymmetry and one was due to discomfort. Removal of the detachable port caused leakage in two EPs, requiring an exchange. Also, one patient had a revisional contralateral 
Table 1 Patient characteristics, time between breast surgery procedure and follow-up (mean \pm SD, range in parenthesis) and BREAST-Q softness question (median, 1q and 3q) for all patients and by breast reconstruction method

\begin{tabular}{|c|c|c|c|c|}
\hline & All patients $n=69$ & $\mathrm{EP} n=28$ & DIEP flap $\mathrm{n}=41$ & p-value ${ }^{b}$ \\
\hline Age (years) & $54 \pm 9.4$ & $56 \pm 9.0$ & $53 \pm 9.5$ & 0.20 \\
\hline $\operatorname{BMI}\left(\mathrm{kg} / \mathrm{m}^{2}\right)$ & $26 \pm 2.9$ & $25 \pm 3.1$ & $26 \pm 2.7$ & 0.23 \\
\hline Breast reconstruction to follow-up (months) & $\begin{array}{l}25 \pm 9.4 \\
(11-56)\end{array}$ & $\begin{array}{l}25 \pm 9.8 \\
(12-56)\end{array}$ & $\begin{array}{l}25 \pm 9.3 \\
(11-50)\end{array}$ & 0.96 \\
\hline Contralateral surgery to follow-up (months) & $\begin{array}{l}18 \pm 8.0 \\
(2-36)\end{array}$ & $\begin{array}{l}15 \pm 5.0 \\
(4-25)\end{array}$ & $\begin{array}{l}21 \pm 9.5 \\
(2-36)\end{array}$ & 0.06 \\
\hline Breast reconstruction to completed BREAST-Q (months) & $\begin{array}{l}24 \pm 10 \\
(8-56)\end{array}$ & $\begin{array}{l}26 \pm 11 \\
(11-56)\end{array}$ & $\begin{array}{l}24 \pm 9.3 \\
(8-50)\end{array}$ & 0.44 \\
\hline $\begin{array}{l}\text { BREAST-Q question } 1 . \mathrm{h}^{\mathrm{a}} \\
\text { "How satisfied or dissatisfied have you been with the softness } \\
\text { of your reconstructed breast (s)?" }\end{array}$ & $3(3,4)$ & $3(3,3)$ & $4(3,4)$ & $<0.01^{\mathrm{c}}$ \\
\hline
\end{tabular}

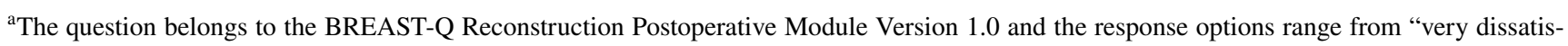
fied" (1) to "very satisfied (4)"

${ }^{\mathrm{b}}$ Student's t-test

${ }^{\mathrm{c}} \mathrm{Chi}^{2}$-test

Abbreviations: $S D$, standard deviation; $1 q$, lower quartile; $3 q$, upper quartile; $B M I$, body mass index; $E P$, expander prosthesis; $D I E P$, deep inferior epigastric perforator

P-values $<0.05$ were considered significant and are in bold

surgery due to volume asymmetry resulting in augmentation with a Mentor ${ }^{\circledR}$ Siltex Round, Moderate Profile, Cohesive I (Johnson \& Johnson Medical Ltd, New Brunswick, NJ, 08,933 , USA).

\section{Objective examinations}

All measurements were performed at the plastic surgery outpatient clinic. Two registered nurses, experienced in breast reconstruction, conducted the examinations according to a study-specific protocol (Appendix). First, measurements were taken with the patient in a sitting position. Breast volumes were determined using plastic breast cups designed by a former plastic surgeon at our clinic (Emballageform AB, Limhamn, Sweden) [19]. Jugulum-nipple distance, clavicular-submammary fold distance and ptosis were assessed with a tape measure. Jugulum-nipple distance measurements were not made in 10 patients who had not chosen to undergo nipple reconstruction. Also, grading according to the Baker classification scale was performed [16].

Applanation tonometry was assessed with the patient in the supine position. A round, plexiglass disc engraved with a circular scale in millimetres was used $[7,15]$. The disc had a weight of $280 \mathrm{~g}$. After moistening the disc with $70 \%$ ethanol, it was placed on the highest part of the breast. From the breast contact area, two perpendicular diameters were identified with the engraved scale and labelled A and B. In accordance with previous studies, the imprint area was calculated according to the formula Area $=\pi \mathrm{AB} / 4$ as the shape of the breast imprint corresponds to that of an ellipse [15]. However, the tonometer area is dependent on the breast volume. To prevent differences in breast volume affecting the comparisons, fractional areas were calculated by dividing the breast area of interest by the sum of the reconstructed and the contralateral breast areas, similar to previous studies $[8,9]$. The higher the fractional area, the softer the breast.

\section{BREAST-Q}

The BREAST-Q Postoperative Reconstruction Module Version 1.0 was given to all patients in connection with the objective evaluation. The module is comprised of QOL domains (Psychosocial Well-being, Sexual Well-being and Physical Well-being) and Satisfaction domains (Satisfaction with Breasts, Satisfaction with nipples, Satisfaction with abdomen, Satisfaction with Outcome and Satisfaction with Care) [2]. Satisfaction with Breasts includes 18 questions which are answered using a 4-point Likert scale: very dissatisfied (1), somewhat dissatisfied (2), somewhat satisfied (3) and very satisfied (4). One patient in the DIEP flap group did not answer the question "How satisfied or dissatisfied have you been with the softness of your reconstructed breast (s)?" Another patient reconstructed with a DIEP flap did not return the questionnaire. The breast reconstruction was performed at a mean of 24 (SD 10) months prior to completing the BREAST-Q, presented in Table 1.

\section{Statistical analysis}

Parametric and non-parametric tests were used for statistical analysis. Data was presented as mean and SD or median and quartiles when appropriate. Group comparisons were 
conducted with the Student's t-test or Mann-Whitney U-test for unpaired samples and the paired t-test or Wilcoxon signed-rank test for paired samples. A chi ${ }^{2}$-test was used for ordinal data. Spearman's rank correlation was used for measuring the association between two variables. A p-value below 0.05 indicated a significant difference. Statistical Package for Social Sciences version 26 (IBM Corp. Armonk, NY: IBM Corp. Released 2019) was used for statistical analysis.

\section{Results}

\section{Objective examinations}

Age and body mass index did not differ between the EP and the DIEP flap groups. The number of months between breast reconstruction and follow-up, contralateral surgery and follow-up, and breast reconstruction and BREAST-Q completion were comparable between the two groups (Table 1).

Breast volume, jugulum-nipple distance, clavicle-submammary fold distance and ptosis were measured on the reconstructed and the contralateral breasts, and ratios were calculated (Table 2). A ratio of 1 equalled symmetry. Breast volumes were somewhat larger in the DIEP flap group. Mean volume ratios were 0.94 and 1.01 in the EP and DIEP flap groups respectively; however, there was no significant difference between the ratios. Jugulum-nipple distance and ptosis ratios, but not clavicular-submammary fold distance, differed significantly between the reconstructed groups, with mean ratios closer to 1 in the DIEP flap group.

All breasts were evaluated according to the Baker scale. No breasts were graded as III or IV.

Breast softness comparisons of EP and DIEP flaps assessed with applanation tonometry are presented in Table 3. The fractional areas were significantly larger in the DIEP flap reconstructed breasts. In both the EP and DIEP flap groups, the tonometric and the fractional areas were significantly larger in the contralateral breasts compared with the reconstructed ones (Table 4). Divided into groups by type of contralateral surgery, contralateral breast reductions but not mastopexies remained significantly larger for all patients $\left(\mathrm{p}_{\text {reduction }}<0.01\right.$ and $\left.\mathrm{p}_{\text {mastopexy }}=0.06\right)$. There were no significant differences between contralateral breast reductions nor mastopexies when compared with the paired EP or the paired DIEP flap reconstructed breasts (Table 5). Tonometric data on the reconstructed breasts were missing from two patients in the EP group.

\section{BREAST-Q softness}

The median response to the BREAST-Q question "How satisfied or dissatisfied have you been with the softness of

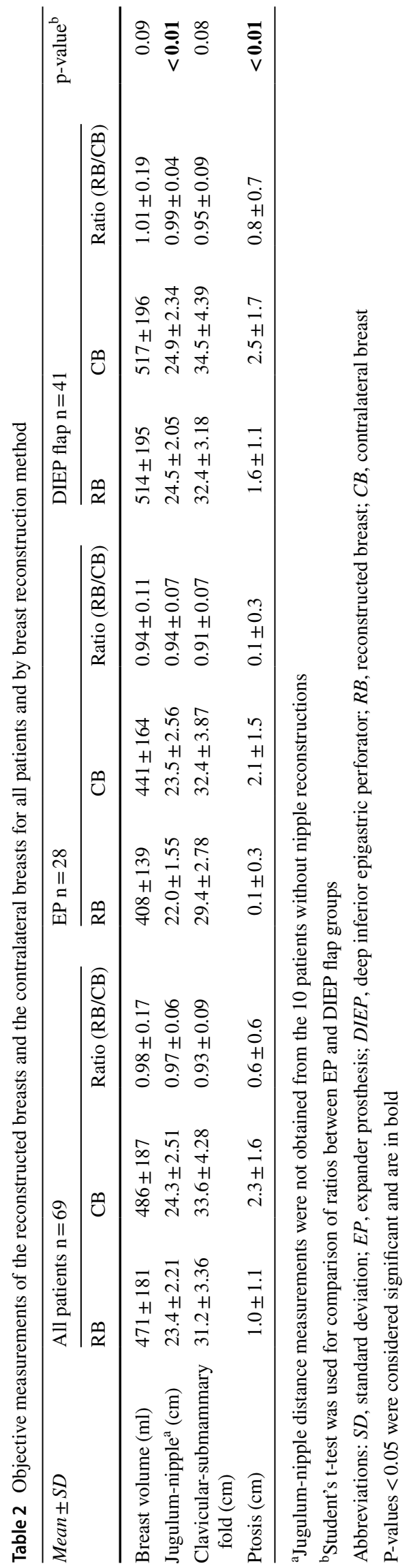


Table 3 Comparisons of breast softness assessed with applanation tonometry between the EP and DIEP flap groups

\begin{tabular}{llll}
\hline & EP $\mathrm{n}=28^{\mathrm{a}}$ & DIEP flap $\mathrm{n}=41$ & $\mathrm{p}^{- \text {value }^{\mathrm{c}}}$ \\
\hline $\begin{array}{llll}\text { Fractional area } \\
\text { Mean } \pm S D\end{array}$ & & & \\
Reconstructed breasts & $0.36 \pm 0.12$ & $0.47 \pm 0.06$ & $<\mathbf{0 . 0 1}$ \\
All contralateral breasts & $0.64 \pm 0.12$ & $0.53 \pm 0.06$ & $<\mathbf{0 . 0 1}$ \\
\hline
\end{tabular}

${ }^{\text {a }}$ Tonometric data from the reconstructed breast were missing from two patients in the EP group

${ }^{b}$ Fractional area $=$ breast area of interest divided by the sum of the reconstructed and contralateral breast areas

${ }^{\mathrm{c}}$ Student's t-test

Abbreviations: $S D$, standard deviation; $E P$, expander prosthesis; $D I E P$, deep inferior epigastric perforator; $R B$, reconstructed breast; $C B$, contralateral breast

$\mathrm{P}$-values $<0.05$ were considered significant and are in bold

your reconstructed breast (s)?" was 3 (lower quartile, upper quartile; 3,3 ) in the EP group, corresponding to "somewhat satisfied", and 4 (lower quartile, upper quartile; 3,4 ) in the DIEP flap group, corresponding to "very satisfied". The DIEP flap group was significantly more satisfied with the softness of their reconstructed breasts in the group comparison $(\mathrm{p}<0.01)$ (Table 1$)$. A fair positive correlation was found between the areas analysed with tonometry in the reconstructed breasts and the BREAST-Q question responses $\left(\mathrm{r}_{\mathrm{s}}=0.37, \mathrm{p}<0.01\right)[20]$.

\section{Discussion}

To our knowledge, this is the first report investigating breast softness following breast reconstruction with an EP or DIEP flaps. In this study, the DIEP flap group had significantly softer breast reconstructions and higher patient-reported satisfaction with breast softness compared with the EP group. A fair correlation was found between the objective measurements and the patient satisfaction regarding breast softness.
Objectively, the non-operated contralateral breasts were significantly softer compared with the breast reconstructions.

Factors determining the final surgical results require further investigation, and therefore softness was chosen to be the focus of this study. As expected, we found DIEP flaps to be softer than an EP. The EP is placed in a submuscular pocket closed with sutures and filled with saline to adopt a projection. The enclosed cavity, together with a high degree of filling, results in a harder breast. In contrast, the DIEP flap consists of abdominal fat and is attached to the chest mainly through intracutaneous sutures enabling a softer composition. As the DIEP flap is softer and more similar to a natural contralateral breast, we were not surprised to find patients were more satisfied in this group. Previous studies have concluded that patients with autologous reconstructed breasts are more satisfied with their breasts than patients with implant-based reconstructions [21, 22]. Liu et al. reported a significantly higher score for "Satisfaction with Breasts" when comparing patients with abdomen-based autologous breast reconstructions and implant-based [22]. Since breast softness is included in the "Satisfaction with Breasts" domain, we believe our finding is in accordance with the aforementioned report. Thus, the degree of correlation between the objective measure and the patient-reported satisfaction regarding softness was interpreted only as fair in this study. Similar weak correlations have been reported in previous reports, thereby illustrating the complexity of measuring patient-reported outcomes [23, 24]. Patient satisfaction is most likely influenced by many different factors, for example the current psychosocial situation, in addition to the objective outcome.

A harder breast in terms of a breast reconstruction or augmentation is most likely a cause of capsular contracture formation, a common complication in breasts with implants [25]. The implant surface and anatomical placement affect the likelihood of capsular contracture. In a study by Handel et al., polyurethane foam-coated implants had a decreased risk for capsular contracture compared with textured and smooth surfaced implants. However, the reports comparing

Table 4 Comparisons of breast softness between the reconstructed and contralateral breasts for all patients and by breast reconstruction method

\begin{tabular}{|c|c|c|c|c|c|c|c|c|c|}
\hline \multirow[b]{2}{*}{$M e a n \pm S D$} & \multicolumn{2}{|c|}{ All patients $n=69^{a}$} & \multirow[t]{2}{*}{ p-value ${ }^{c}$} & \multicolumn{2}{|l|}{$\mathrm{EP} \mathrm{n}=28^{\mathrm{a}}$} & \multirow[t]{2}{*}{ p-value ${ }^{c}$} & \multicolumn{2}{|c|}{ DIEP flap $n=41$} & \multirow[t]{2}{*}{ p-value } \\
\hline & $\mathrm{RB}$ & $\mathrm{CB}$ & & $\mathrm{RB}$ & $\mathrm{CB}$ & & $\mathrm{RB}$ & $\mathrm{CB}$ & \\
\hline Tonometric areas $\left(\mathrm{cm}^{2}\right)$ & $50.3 \pm 20.2$ & $64.5 \pm 19.5$ & $<0.01$ & $32.5 \pm 11.4$ & $59.6 \pm 24.3$ & $<0.01$ & $61.6 \pm 16.0$ & $67.8 \pm 14.8$ & $<0.01$ \\
\hline Fractional areas ${ }^{\mathrm{b}}$ & $0.43 \pm 0.11$ & $0.57 \pm 0.11$ & $<0.01$ & $0.36 \pm 0.12$ & $0.64 \pm 0.12$ & $<0.01$ & $0.47 \pm 0.06$ & $0.53 \pm 0.06$ & $<0.01$ \\
\hline
\end{tabular}

${ }^{\mathrm{a}}$ Tonometric data from the reconstructed breast were missing from two patients in the EP group

${ }^{b}$ Fractional area $=$ breast area of interest divided by the sum of the reconstructed and contralateral breast areas

${ }^{\mathrm{c}}$ Paired t-test for pairwise comparisons between the reconstructed (RB) and the contralateral breast (CB)

Abbreviations: $S D$, standard deviation; $E P$, expander prosthesis; $D I E P$, deep inferior epigastric perforator; $R B$, reconstructed breast; $C B$, contralateral breast

P-values $<0.05$ were considered significant and are in bold 
Table 5 Comparisons of breast softness in reconstructed and contralateral breasts divided into groups by prevalence and type of contralateral surgery and by breast reconstruction method

\begin{tabular}{|c|c|c|c|c|c|}
\hline \multirow[b]{2}{*}{$\begin{array}{l}\text { Fractional area } \\
\text { Median }(1 q, 3 q)\end{array}$} & All patients ${ }^{\mathrm{a}}$ & p-value ${ }^{c}$ & EP $^{\mathrm{a}} \quad$ p-value $^{\mathrm{c}}$ & DIEP flap & p-value ${ }^{c}$ \\
\hline & & & & & \\
\hline $\begin{array}{l}\text { Non-operated } \\
\text { contralateral, } \mathbf{n}\end{array}$ & $38 / 38$ & & $13 / 38$ & $25 / 38$ & \\
\hline $\begin{array}{l}\mathrm{RB} \\
\mathrm{CB}\end{array}$ & $\begin{array}{l}0.45(0.34,0.49) \\
0.55(0.51,0.66)\end{array}$ & $<0.01$ & $\left.\begin{array}{l}0.32(0.27,0.37) \\
0.68(0.63,0.73)\end{array}\right\}<\mathbf{0 . 0 1}$ & $\begin{array}{l}0.48(0.44,0.51) \\
0.53(0.49,0.56)\end{array}$ & \} 0.05 \\
\hline $\begin{array}{l}\text { Operated } \\
\text { contralateral, } \mathbf{n}\end{array}$ & $31 / 31$ & & $15 / 31$ & $16 / 31$ & \\
\hline $\begin{array}{l}\mathrm{RB} \\
\mathrm{CB}\end{array}$ & $\begin{array}{l}0.43(0.33,0.49) \\
0.57(0.51,0.67)\end{array}$ & $<0.01$ & $\left.\begin{array}{l}0.33(0.30,0.47) \\
0.67(0.53,0.70)\end{array}\right\} \quad \mathbf{0 . 0 1}$ & $\begin{array}{l}0.46(0.42,0.50) \\
0.54(0.50,0.58)\end{array}$ & \} 0.05 \\
\hline Reduction, $\mathbf{n}$ & $24 / 24$ & & $9 / 24$ & $15 / 24$ & \\
\hline $\begin{array}{l}\mathrm{RB} \\
\mathrm{CB}\end{array}$ & $\begin{array}{l}0.44(0.34,0.50) \\
0.56(0.50,0.67)\end{array}$ & $<0.01$ & $\left.\begin{array}{l}0.34(0.30,0.44) \\
0.66(0.56,0.70)\end{array}\right\} \quad 0.09$ & $\begin{array}{l}0.46(0.41,0.50) \\
0.54(0.50,0.59)\end{array}$ & \} 0.07 \\
\hline Mastopexy, n & $7 / 7$ & & $6 / 7$ & $1 / 7$ & \\
\hline $\begin{array}{l}\mathrm{RB} \\
\mathrm{CB}\end{array}$ & $\begin{array}{l}0.33(0.30,0.49) \\
0.67(0.51,0.70)\end{array}$ & 0.06 & $\left.\begin{array}{l}0.33(0.28,0.50) \\
0.67(0.50,0.72)\end{array}\right\} \quad 0.07$ & $\begin{array}{l}0.47 \\
0.53\end{array}$ & \\
\hline
\end{tabular}

${ }^{a}$ Values missing from two patients reconstructed with an EP

${ }^{b}$ Fractional area $=$ breast area of interest divided by the sum of the reconstructed and contralateral breast areas

${ }^{\mathrm{c}}$ Wilcoxon signed-rank test

Abbreviations: $1 q$, lower quartile; $3 q$, upper quartile; $E P$, expander prosthesis; DIEP, deep inferior epigastric perforator; $R B$, reconstructed breast; $C B$, contralateral breast

$\mathrm{P}$-values $<0.05$ were considered significant and are in bold

capsular contracture following textured and smooth implant insertions are conflicting $[6,9,25,26]$. Placement of the implant in the submuscular position was found to decrease the risk of capsular contracture in another report [27]. Moreover, RT as well as breast reconstruction, when compared with augmentation, increased the risk for capsular contracture $[13,25,28]$. In this study, the EP used had a textured surface, all implants were placed in the submuscular position and no patients underwent RT. Nonetheless, two of the six prosthesis exchanges were due to capsular contracture, and no breasts were assessed as Baker grades III or IV at the objective examinations.

Based on the findings from the objective evaluations, a DIEP flap, overall, was more symmetrical with its contralateral breast compared with an EP. Symmetry in breasts reconstructed with pedicled or free TRAM flaps has been evaluated by Edsander-Nord et al. using objective methods [15]. They report a higher level of symmetry in free TRAM flap reconstructed breasts, most pronounced for breast volume and softness [15]. Similar to this study, the free autologous method provided the most symmetrical results. In our analysis however, breast volume was the only measurement that did not differ between the EP and DIEP flap groups, probably as a result of symmetrising contralateral surgery. Although it is possible to improve volume symmetry with surgery, other aspects such as ptosis are more difficult to correct. In the past, symmetry after breast surgery has been objectively evaluated with various modalities. Volumetric symmetry after breast reconstruction has been studied using magnetic resonance imaging and three-dimensional imaging [24, 29]. Software programmes like breast cancer conservation treatment cosmetic results (BCCT.core) and the breast analysing tool (BAT ${ }^{\circledR}$ ) have been developed and improved for breast symmetry assessment [30-32]. The BCCT.core and BAT® calculate asymmetry parameters in digital photographs, and in addition the BCCT.core assesses skin colour and scar visibility [30, 31]. Yet none of these software programmes has been validated for breast reconstruction.

Natural breasts are composed of fat, and glandular and ductal tissue whereas a DIEP flap consists of abdominal fat. Hence, one could expect a natural breast to be firmer. However, our findings indicate the opposite, except in the group with operated contralateral breasts, in which no difference was found. With a mean age of 54 (SD 9.4) years at follow-up, a plausible explanation might be the changes in the breast composition that occur in older women. During menopause, the breast undergoes involution of ductal and glandular tissues. With age the amount of breast fat decreases and supporting Cooper ligaments relax, resulting in a looser and softer breast composition [33].

A strength of this study is its randomised and prospective design and the high participation rate as only four patients did not complete objective evaluations. To mitigate measurement variability, the evaluations were performed by one of two nurses experienced in breast reconstruction. The use of 
the validated BREAST-Q questionnaire is also a strength, although we chose to use only one question.

A limitation is that no interobserver agreement was tested for the objective examinations. A recently published study reported low interobserver agreement for grading capsular contracture according to the Baker scale, emphasising the importance of this matter [17]. In order to strengthen the role of applanation tonometry as an objective breast softness measurement tool, an assessment of the interobserver agreement is warranted. Additionally, the broad time interval between breast reconstruction and follow-up could have had an impact on our findings as a breast reconstruction changes over time.

\section{Conclusions}

In regard to breast softness, this study reports DIEP flaps to be objectively softer than an EP and to give higher patientreported satisfaction. The fair correlation found between the two measures suggests that there are factors other than those objectively measured that influence patient-reported satisfaction. However, further investigation is warranted for evaluation of the interobserver agreement regarding applanation tonometry.

Supplementary Information The online version contains supplementary material available at https://doi.org/10.1007/s00238-021-01835-z.

Acknowledgements We are most grateful to nurses Malin Levin and Lise-Lotte Mulder at the Department of Plastic and Reconstructive Surgery, Skåne University Hospital, Malmö, for their work and contribution to the data collection.

Funding Open access funding provided by Lund University.

\section{Declarations}

Ethical approval The procedures were in accordance with the Declaration of Helsinski of 1964 and its most recent revision in 2013. The study was approved by the Regional Ethical Review Board in Lund, Sweden (ref no. 2012/187).

Patient consent All participants were asked to participate in the study and gave their written informed consent if they wanted to participate.

Informed consent Informed consent was obtained from all individual participants included in the study.

Conflict of interest Linda Tallroth, Håkan Brorson, Nathalie Mobargha, Patrik Velander, Stina Klasson and Magnus Becker declare no conflict of interest.

Open Access This article is licensed under a Creative Commons Attribution 4.0 International License, which permits use, sharing, adaptation, distribution and reproduction in any medium or format, as long as you give appropriate credit to the original author(s) and the source, provide a link to the Creative Commons licence, and indicate if changes were made. The images or other third party material in this article are included in the article's Creative Commons licence, unless indicated otherwise in a credit line to the material. If material is not included in the article's Creative Commons licence and your intended use is not permitted by statutory regulation or exceeds the permitted use, you will need to obtain permission directly from the copyright holder. To view a copy of this licence, visit http://creativecommons.org/licenses/by/4.0/.

\section{References}

1. Yoon AP, Qi J, Brown DL, Kim HM, Hamill JB, Erdmann-Sager J et al (2018) Outcomes of immediate versus delayed breast reconstruction: Results of a multicenter prospective study. Breast (Edinburgh, Scotland) 37:72-79

2. Pusic AL, Klassen AF, Scott AM, Klok JA, Cordeiro PG, Cano SJ (2009) Development of a new patient-reported outcome measure for breast surgery: the BREAST-Q. Plast Reconstr Surg 124(2):345-353

3. Klassen AF, Pusic AL, Scott A, Klok J, Cano SJ (2009) Satisfaction and quality of life in women who undergo breast surgery: a qualitative study. BMC Womens Health 9:11

4. Pusic AL, Chen CM, Cano S, Klassen A, McCarthy C, Collins ED et al (2007) Measuring quality of life in cosmetic and reconstructive breast surgery: a systematic review of patient-reported outcomes instruments. Plast Reconstr Surg 120(4):823-37. discussion 38-9

5. Edsander-Nord A, Bjorklund T, Jurell G, Wickman M (2004) Objective evaluation of two differently-shaped permanent expander prostheses used for breast reconstruction. Scand J Plast Reconstr Surg Hand Surg 38(4):204-8

6. Fagrell D, Berggren A, Tarpila E (2001) Capsular contracture around saline-filled fine textured and smooth mammary implants: a prospective 7.5-year follow-up. Plast Reconstr Surg 108(7):2108-12. discussion 13

7. Gylbert LO (1989) Applanation tonometry for the evaluation of breast compressibility. Scand J Plast Reconstr Surg Hand Surg 23(3):223-9

8. Hakelius L, Ohlsen L (1992) A clinical comparison of the tendency to capsular contracture between smooth and textured gel-filled silicone mammary implants. Plast Reconstr Surg 90(2):247-254

9. Hakelius L, Ohlsen L (1997) Tendency to capsular contracture around smooth and textured gel-filled silicone mammary implants: a five-year follow-up. Plast Reconstr Surg 100(6):1566-1569

10. Minami E, Koh IH, Ferreira JC, Waitzberg AF, Chifferi V, Rosewick TF et al (2006) The composition and behavior of capsules around smooth and textured breast implants in pigs. Plast Reconstr Surg 118(4):874-884

11. Wickman M (1993) Comparison between rapid and slow tissue expansion in breast reconstruction. Plast Reconstr Surg 91(4):663-70. discussion 71-2

12. Wickman M, Jurell G (1997) Low capsular contraction rate after primary and secondary breast reconstruction with a textured expander prosthesis. Plast Reconstr Surg 99(3):692-697

13. Benediktsson K, Perbeck L (2006) Capsular contracture around saline-filled and textured subcutaneously-placed implants in irradiated and non-irradiated breast cancer patients: five years of monitoring of a prospective trial. J Plast Reconstr Aesthet Surg 59(1):27-34

14. Moore JR (1979) Applanation tonometry of breasts. Plast Reconstr Surg 63(1):9-12 
15. Edsander-Nord A, Brandberg Y, Wickman M (2001) Quality of life, patients' satisfaction, and aesthetic outcome after pedicled or free TRAM flap breast surgery. Plast Reconstr Surg 107(5):114253. discussion 54-5

16. Spear SL, Baker JL Jr (1995) Classification of capsular contracture after prosthetic breast reconstruction. Plast Reconstr Surg 96(5):1119-23. discussion 24

17. de Bakker E, Rots M, Buncamper ME, Niessen FB, Smit JM, Winters HAH et al (2020) The Baker classification for capsular contracture in breast implant surgery is unreliable as a diagnostic tool. Plast Reconstr Surg 146(5):956-962

18. Tallroth L, Velander P, Klasson S (2020) A short-term comparison of expander prosthesis and DIEP flap in breast reconstructions: A prospective randomized study. J Plast Reconstr Aesthet Surg 12:S1748-6815(20)30598-2. https://doi.org/10.1016/j.bjps.2020. 10.104

19. Hansson E, Manjer J, Ringberg A (2014) Reliability of plastic cups to measure breast volume. J Plast Surg Hand Surg 48(4):254-258

20. White SE (2020) Summarizing Data \& Presenting Data in Tables \& Graphs. Basic \& Clinical Biostatistics, 5th edn. McGraw-Hill Education, New York

21. Santosa KB, Qi J, Kim HM, Hamill JB, Wilkins EG, Pusic AL (2018) Long-term patient-reported outcomes in postmastectomy breast reconstruction. JAMA Surg 153(10):891-899

22. Liu C, Zhuang Y, Momeni A, Luan J, Chung MT, Wright E et al (2014) Quality of life and patient satisfaction after microsurgical abdominal flap versus staged expander/implant breast reconstruction: a critical study of unilateral immediate breast reconstruction using patient-reported outcomes instrument BREAST-Q. Breast Cancer Res Treat 146(1):117-126

23. Heil J, Dahlkamp J, Golatta M, Rom J, Domschke C, Rauch G et al (2011) Aesthetics in breast conserving therapy: do objectively measured results match patients' evaluations? Ann Surg Oncol 18(1):134-138

24. Yip JM, Watson DI, Tiggemann M, Hsia S, Smallman AE, Dean NR (2015) Determinants of breast reconstruction outcome: how important is volume symmetry? J Plast Reconstr Aesthet Surg 68(5):679-685
25. Handel N, Cordray T, Gutierrez J, Jensen JA (2006) A long-term study of outcomes, complications, and patient satisfaction with breast implants. Plast Reconstr Surg 117(3):757-67. discussion $68-72$

26. Stevens WG, Nahabedian MY, Calobrace MB, Harrington JL, Capizzi PJ, Cohen R et al (2013) Risk factor analysis for capsular contracture: a 5-year Sientra study analysis using round, smooth, and textured implants for breast augmentation. Plast Reconstr Surg 132(5):1115-1123

27. Henriksen TF, Fryzek JP, Holmich LR, McLaughlin JK, Kjoller K, Hoyer AP et al (2005) Surgical intervention and capsular contracture after breast augmentation: a prospective study of risk factors. Ann Plast Surg 54(4):343-351

28. Ringberg A, Tengrup I, Aspegren K, Palmer B (1999) Immediate breast reconstruction after mastectomy for cancer. Eur J Surg Oncol 25(5):470-476

29. Cohen O, Small K, Lee C, Petruolo O, Karp N, Choi M (2016) Is unilateral implant or autologous breast reconstruction better in obtaining breast symmetry? Breast J 22(1):75-82

30. Cardoso MJ, Cardoso J, Amaral N, Azevedo I, Barreau L, Bernardo $M$ et al (2007) Turning subjective into objective: the BCCT.core software for evaluation of cosmetic results in breast cancer conservative treatment. Breast (Edinburgh, Scotland) 16(5):456-61

31. Fitzal F, Krois W, Trischler H, Wutzel L, Riedl O, Kuhbelbock $\mathrm{U}$ et al (2007) The use of a breast symmetry index for objective evaluation of breast cosmesis. Breast (Edinburgh, Scotland) 16(4):429-435

32. Krois W, Romar AK, Wild T, Dubsky P, Exner R, Panhofer P et al (2017) Objective breast symmetry analysis with the breast analyzing tool (BAT): improved tool for clinical trials. Breast Cancer Res Treat 164(2):421-427

33. Pandya S, Moore RG (2011) Breast development and anatomy. Clin Obstet Gynecol 54(1):91-95

Publisher's note Springer Nature remains neutral with regard to jurisdictional claims in published maps and institutional affiliations. 